\title{
In vivo testing of crosslinked polyethers. II. Weight loss, IR analysis, and swelling behavior after implantation
}

\author{
B. J. M. Pol ${ }^{1, *}$ P. B. van Wachem, ${ }^{2}$ L. van der Does, ${ }^{1}$ and A. Bantjes ${ }^{1}$ \\ ${ }^{1}$ University of Twente, Department of Chemical Technology, Biomaterials Section, PO Box 217, 7500 AE Enschede; \\ ${ }^{2}$ Groningen University, Laboratory for Cell Biology and Electron Microscopy, Oostersingel 69/2, 9713 EZ Groningen, \\ The Netherlands
}

As reported in Part I ("In vivo testing of crosslinked polyethers. I. Tissue reactions and biodegradation," J. Biomed. Mater. Res., this issue, pp. 307-320), microscopical evaluation after implantation of crosslinked (co)polyethers in rats showed differences in the rate of biodegradation, depending on the presence of tertiary hydrogen atoms in the main chain and the hydrophilicity of the polyether system. In this article (Part II) the biostability will be discussed in terms of weight loss, the swelling behavior, and changes in the chemical structure of the crosslinked polyethers after implantation. The biostability increased in the order poly $(\mathrm{POx})<$ poly (THF-co-OX) < poly(THF) for the relatively hydropho- bic polyethers. This confirmed our hypothesis that the absence of tertiary hydrogen atoms would improve the biostability. On the other hand, signs of biodegradation were observed for all polyether system studied. Infrared surface analysis showed that biodegradation was triggered by oxidative attack on the polymeric chain, leading to the formation of carboxylic ester and acid groups. It also was found that in the THF-based (co)polyethers, $\alpha$-methylene groups were more sensitive than $\beta$-methylene groups. For a hydrophilic poly(THF)/PEO blend, an increase in surface PEO content was found, which might be due to preferential degradation of the PEO domains. (c) 1996 John Wiley \& Sons, Inc.

\section{INTRODUCTION}

In Part I the tissue reactions and the biodegradation upon implantation of several crosslinked (co)polyethers in rats were evaluated by light microscopy (LM) and transmission electron microscopy (TEM). ${ }^{15}$ (Co)polyethers with and without tertiary hydrogen atoms in the main chain and differing in hydrophilicity were tested (Table I). In general, all polyethers showed good biocompatibility, i.e., no indications of release of cytotoxic compounds and/or complement activation were found with low neutrophil and macrophage infiltration, quiet giant cell reaction, and formation of a thin fibrous capsule. Poly(POx) and PEO were the most sensitive to biodegradation.

In the long term in vivo application knowledge about the relationship of polymeric implants to biodegradation is essential. In particular, the in vivo and in vitro biodegradation of segmented poly(ether urethane)s to be used in biomedical applications are of current interest. ${ }^{1-14}$ The mechanisms of in vivo degradation are still largely unknown due to the complex dynamic and interactive responses of the host organism

*To whom correspondence should be addressed. to an implant. Hydrolysis (specifically enzymatic) of the urethane and urea bonds was proposed, ${ }^{2,3}$ whereas the polyether segment was considered to be relatively stable against hydrolytic degradation. ${ }^{4,5}$ However, the polyether segment has been reported to be sensitive to oxidation reactions. ${ }^{2-4,6-9}$ Testing of high molecular weight (crosslinked) polyethers, i.e., in the absence of the polyurethane hard segment, might lead to a better understanding of the sensitivity of polyethers to biodegradation.

In this article (Part II) the weight loss, the swelling behavior of the crosslinked polyethers, and the changes in the chemical structure of the surface after implantation will be described and possible degradation mechanisms will be discussed.

\section{MATERIALS AND METHODS}

\section{Materials}

The synthesis and/or molecular weight characteristics of poly(POx), poly(THF), poly(THF-co-OX) (17 mole $\%$ oxetane units), and the PEO sample were described in Part I. ${ }^{15}$ 
TABLE I

Structures of $(\mathrm{Co})$ Polyethers

\begin{tabular}{ll}
\hline Poly(POx): & $-\left(\mathrm{CH}_{2} \mathrm{CH}-\mathrm{O}\right)_{\mathrm{n}^{-}}$ \\
& \\
& $\mathrm{CH}_{3}$ \\
Poly(THF): & $-\left(\mathrm{CH}_{2} \mathrm{CH}_{2} \mathrm{CH}_{2} \mathrm{CH}_{2}-\mathrm{O}\right)_{\mathrm{n}^{-}}$ \\
Poly(THF-co-OX): & $-\left(\mathrm{CH}_{2} \mathrm{CH}_{2} \mathrm{CH}_{2} \mathrm{CH}_{2}-\mathrm{O}\right)_{\mathrm{n}^{-}}-\left(\mathrm{CH}_{2} \mathrm{CH}_{2} \mathrm{CH}_{2}-\mathrm{O}\right)_{\mathrm{m}^{-}}$ \\
PEO: & $-\left(\mathrm{CH}_{2} \mathrm{CH}_{2}-\mathrm{O}\right)_{\mathrm{n}^{-}}$ \\
\hline
\end{tabular}

\section{Methods}

\section{Sample preparation}

The preparation, crosslinking, and extraction of solution-cast polymer films were carried out as described in Part $\mathrm{I}^{15}$ For in vivo experiments and for testing the reference samples, disks with a diameter of $7-10 \mathrm{~mm}$ were punched from the dried films $(7 \mathrm{~mm}$ for $\mathrm{PEO}, 9 \mathrm{~mm}$ for the poly(THF)/PEO blend, and $10 \mathrm{~mm}$ for the others).

The disks were sterilized with ethylene oxide by a standard procedure $\left(5 \mathrm{~h}\right.$ at $55^{\circ} \mathrm{C}$ in an ethylene oxide atmosphere at a relative humidity of $70 \%$ ), followed by aeration of the samples with an air flow of $\pm 50^{\circ} \mathrm{C}$ at atmospheric pressure for $48 \mathrm{~h}$ to remove residual ethylene oxide. Subsequently the disks were equilibrated in phosphate-buffered saline (PBS, NPBI, Emmer-Compascuum, The Netherlands) at $37^{\circ} \mathrm{C}$ for 3 days.

From the dried films the water content was determined after equilibrating parts of the films in water at $37^{\circ} \mathrm{C}$ for 2 days. The water content was calculated as the weight percentage of the water in the swollen sample.

\section{Implantations}

The implantation procedure in male PVG-E rats of approximately 3 months of age was described in Part I. ${ }^{15}$ The rats were sacrificed after 4 days, 4 weeks, or 12 weeks, and the implants with surrounding tissue were harvested. Not implanted (reference) samples were kept in PBS at $37^{\circ} \mathrm{C}$ for 4 days, 4 weeks, or 12 weeks for IR surface analysis and analysis of swelling behavior.

Weight loss, IR analysis, and swelling experiments

Explanted samples and reference samples were treated with a $0.3 \%(\mathrm{w} / \mathrm{v})$ solution of collagenase (type 1, Sigma, St. Louis, USA) in PBS at $37^{\circ} \mathrm{C}$ for 4 days, with the collagenase solution being refreshed after 2 days. Then after the 4 days the samples were rinsed thoroughly with distilled water and dried to constant weight in vacuo at $40^{\circ} \mathrm{C}$. From the weight before implantation $\left(W_{1}\right)$ and the weight after implantation $\left(W_{2}\right)$ the weight loss was determined $\left[\left(W_{1}-W_{2}\right) / W_{1}(\times 100 \%)\right]$.
Macroscopically the films were observed upon their appearance.

FT-ATR-IR spectra of the samples were recorded on a Biorad Digilab FTS-60 spectrophotometer equipped with a horizontal-ATR device. KRS-5 was used as the internal reflection element under a $45^{\circ}$ endface angle.

The samples then were extracted with a solvent (toluene for poly(THF), poly(THF-co-OX), and poly(POx); dichloromethane for the poly(THF)/PEO blend; and water for PEO) for 3 days and the weight of the swollen samples $\left(W_{\mathrm{sw}}\right)$ was measured. The samples were dried to constant weight $\left(\mathrm{W}_{\mathrm{dry}}\right)$ in vacuo at $40^{\circ} \mathrm{C}$. The swelling was calculated by the weight ratio of the swollen and dried film $\left(\mathrm{W}_{\mathrm{sw}} / \mathrm{W}_{\text {dry }}\right)$ and the sol fraction by the ratio of the weight loss due to extraction and the weight of the sample before extraction $\left[\left(\mathrm{W}_{2}-\mathrm{W}_{\mathrm{dry}}\right) / \mathrm{W}_{2}(\times 100 \%)\right]$.

\section{RESULTS}

\section{Macroscopic evaluation, weight loss, swelling, and sol fraction}

The values for the water content for poly(POx), poly(THF), and poly(THF-co-OX) amounted to 1-3 $\mathrm{wt} \%$ water, whereas PEO and the poly(THF)/PEO blend contained 63 and $30 \mathrm{wt} \%$ water, respectively. Therefore a distinction is made between hydrophilic materials, PEO and the poly(THF)/PEO blend, and hydrophobic materials, poly(POx), poly(THF), and poly(THF-co-OX). In Table II the macroscopic observations of the explanted samples are presented together with the weight loss, the swelling behavior, and the sol fraction after extraction. For comparison, the results of the reference samples also are given.

\section{Hydrophobic materials}

The in vivo samples of poly(POx) had lost much of their initial weight and had become more fragile/brittle with increasing implantation time. When the 1month and 3-month samples were put in toluene, the amount of absorbed solvent was very high. The swollen samples became intractable and fell apart when we tried to determine the $\mathrm{W}_{\mathrm{sw}}$. The experiments with the reference samples in PBS at $37^{\circ} \mathrm{C}$ resulted in high weight losses, swelling ratios, and sol fractions. Apparently the poly(POx) degrades in vivo as well as under the conditions used for the reference samples.

The in vivo samples of poly(THF) became somewhat bubblelike, foamy, after 1 month, resulting in a decreased transparency. With increasing implantation time, the increase in weight loss, in swelling, and in the sol fraction for the in vivo samples was higher than they were for the references. However, compared to poly(POx), poly(THF) appeared to be much more stable in vivo as well as under the reference conditions. 
TABLE II

Macroscopic Evaluation of Weight Loss, Swelling, and Sol Fraction of Explanted in vivo and Reference (Ref.) Samples

\begin{tabular}{|c|c|c|c|c|c|c|c|}
\hline & \multirow{2}{*}{$\begin{array}{l}\text { Macroscopic Evaluation of Explanted films: (Reference } \\
\text { Samples in Parentheses) }\end{array}$} & \multicolumn{2}{|c|}{$\begin{array}{l}\text { Weight Loss } \\
\left(W_{1}-W_{2}\right) / W_{1} \\
(\times 100 \%)\end{array}$} & \multicolumn{2}{|c|}{$\begin{array}{l}\text { Swelling } \\
\mathrm{W}_{\mathrm{sw}} / \mathrm{W}_{\mathrm{dry}}\end{array}$} & \multicolumn{2}{|c|}{$\begin{array}{c}\text { Sol Fraction } \\
\left(W_{2}-W_{\mathrm{dry}}\right) / \\
W_{2} \\
(\times 100 \%)\end{array}$} \\
\hline & & in vivo & Ref. & in vivo & Ref. & in vivo & Ref. \\
\hline poly $(P O x)$ & $\begin{array}{l}\text { (All reference samples: opaque and somewhat crumpled } \\
\text { surface) }\end{array}$ & & & & & & \\
\hline 4 days: & Opaque and somewhat crumpled surface & 22 & 4.8 & 39 & 30 & 43 & 28 \\
\hline 1 month: & Opaque, rough, crumpled surface, fragile film & 31 & 16 & $\mathrm{nd}^{\mathrm{b}}$ & 35 & nd & 36 \\
\hline 3 months: & Opaque, rough, crumpled surface, fragile film, fell apart & 41 & 22 & nd & 45 & nd & 55 \\
\hline $\operatorname{poly}(T H F):$ & $\begin{array}{l}\text { (All reference samples: transparent with smooth } \\
\text { surface) }\end{array}$ & & & & & & \\
\hline 4 days: & Transparent with smooth surface & 0 & 0 & 4.10 & 4.19 & 0.5 & 1.0 \\
\hline 1 month: & Slightly bubble-like, foamy structure & 2.7 & 0.2 & 5.26 & 4.46 & 9.4 & 1.5 \\
\hline 3 months: & Bubble-like, foamy structure, less stiff than at 1 month & 7.5 & 0.2 & 5.95 & 4.54 & 14.3 & 1.7 \\
\hline $\operatorname{poly}($ THF-co-OX): & $\begin{array}{l}\text { (All reference samples: transparent with smooth } \\
\text { surface) }\end{array}$ & & & & & & \\
\hline 4 days: & Transparent with smooth surface & 0.6 & 0.6 & 4.69 & 4.78 & 1.0 & 1.2 \\
\hline 1 month: & Bubble-like, foamy structure & 4.2 & 0.6 & 5.40 & 4.81 & 15.4 & 1.3 \\
\hline 3 months: & $\begin{array}{l}\text { More pronounced bubble-like, foamy structure, less stiff } \\
\text { than at } 1 \text { month }\end{array}$ & 8.2 & 1.2 & 6.91 & 5.15 & 22.1 & 3.6 \\
\hline PEO: & $\begin{array}{l}\text { (References: white solid films with slightly irregular } \\
\text { surface, 3-month reference had shrunk) }\end{array}$ & & & & & & \\
\hline 4 days: & Slightly brownish, same surface structure as control & $-2.0^{c}$ & 8 & 2.87 & 3.07 & 0.1 & 0.2 \\
\hline 1 month: & Brownish, deviant surface structure & $-57^{c}$ & 14 & 2.15 & 3.25 & 0.3 & 0.2 \\
\hline 3 months: & Brown lump & $-27^{c}$ & 35 & 2.40 & 3.78 & 0.2 & 0.1 \\
\hline poly (THF)/PEO blend: & (All reference samples: opaque with smooth surface) & & & & & & \\
\hline 4 days: & Opaque & 0.8 & 1.4 & 6.73 & 6.64 & 0.5 & 0.5 \\
\hline 1 month: & Very slightly brownish & $-1.2^{\mathrm{c}}$ & 2.8 & 7.02 & 6.87 & 12.8 & 0.8 \\
\hline 3 months: & Slightly brownish & 2.9 & 4.5 & 7.19 & 7.52 & 8.4 & 2.1 \\
\hline
\end{tabular}

${ }^{a}$ Measured in toluene for poly(POx), poly (THF), and poly(THF-co-OX), in water for PEO, and in dichloromethane for poly(THF)/PEO.

${ }^{\mathrm{b}} \mathrm{nd}=$ not determined because sample fell apart.

Negative weight loss means weight increase.

Similar to poly(THF), the in vivo samples of poly(THF-co-OX) showed a bubblelike, foamy structure after 1 month. The weight loss, the increase in swelling, and the sol fraction for both the in vivo and reference samples were slightly higher than for the poly (THF).

\section{Hydrophilic materials}

The weight of the explanted PEO samples was higher than the weight of the implanted samples. Light microscopic evaluation of the 3-month in vivo PEO implantation sample revealed that not all cellular material was removed by the collagenase treatment, which might explain the increase $(27 \%)$ in weight as well as the brownish color. For the reference samples, both the weight loss and the swelling increased with time of treatment in PBS. After 3 months $35 \%$ of the initial weight was lost and the sample had shrunk considerably.
Because of the increase in weight found for the in vivo samples of $\mathrm{PEO}$, care must be taken when interpreting the in vivo results of the PEO-containing blends. As for the PEO samples, all cellular material might not have been removed by the collagenase treatment, which also is indicated by the slight brownish color. For the reference samples, an increase in weight loss, swelling, and sol fraction were found as the treatment time increased. Considering the small weight loss of the poly(THF) reference after 3 months, and a corresponding high value for the PEO reference, the $4.5 \%$ weight loss for the blend may be ascribed predominantly to degradation of the PEO fraction.

\section{Surface analysis (IR)}

In order to get information about the mechanism by which (bio)degradation had taken place, ATR-IR analysis was performed. Because of the weight increase found for the explanted PEO samples, their IR spectra 
TABLE III

IR Assignment of New Absorptions

\begin{tabular}{|c|c|}
\hline Absorption $\left(\mathrm{cm}^{-1}\right)$ & Possible Assignments ${ }^{16-18}$ \\
\hline $\pm 3600-3100$ & $\begin{array}{l}\mathrm{O}-\mathrm{H} \text { stretch of acid, alcohol (or } \\
\text { hydroperoxide) }\end{array}$ \\
\hline \pm 1730 & $\begin{array}{l}\mathrm{C}=\mathrm{O} \text { stretch of carboxylic ester or } \\
\text { aldehyde }\end{array}$ \\
\hline \pm 1655 & $\begin{array}{l}\mathrm{C}=\mathrm{O} \text { stretch of } \mathrm{COOH}^{1,7} \\
\mathrm{C}=\mathrm{C} \text { stretch alkene } \\
\text { (or } \mathrm{C}=\mathrm{O} \text { of amide } \mathrm{I})^{12}\end{array}$ \\
\hline \pm 1540 & $\mathrm{C}-\mathrm{N}-\mathrm{H}$ (stretch-bend) (amide II) ${ }^{12}$ \\
\hline \pm 1170 & $\begin{array}{l}\mathrm{O}-\mathrm{C}-\mathrm{O} \text { asym. stretch of ester }{ }^{10} \text { or } \\
\text { carboxylic acid }{ }^{17}\end{array}$ \\
\hline
\end{tabular}

were difficult to interpret and therefore will not be discussed.

In Table III values are given for new absorptions observed on the polymer surfaces and their possible assignments are outlined.
Hydrophobic materials

As an example of the surface changes of poly(POx), the spectrum of the 3-month in vivo sample is given in Figure 1 as is the 3-month reference. Already after 4 days small peaks at $1730 \mathrm{~cm}^{-1}$ and $1655 \mathrm{~cm}^{-1}$ were present for the in vivo sample. The intensity of the peak at $1730 \mathrm{~cm}^{-1}$ remained approximately the same for the 4-day, the 1-month, and the 3-month in vivo samples, whereas the intensity of the $1655 \mathrm{~cm}^{-1}$ peak increased significantly. No reference sample showed any absorption at $1730 \mathrm{~cm}^{-1}$ or at $1655 \mathrm{~cm}^{-1}$, indicating that the presence of these peaks was caused by biodegradation. Also, in contrast to the reference samples, an increase of a broad band at $3600-3100 \mathrm{~cm}^{-1}$ was observed for the in vivo samples (see Fig. 2).

In Figure 1 the spectra of the in vivo samples of poly (THF) are given together with that of the 3-month reference. While after 4 days in vivo only a very small absorption at $1730 \mathrm{~cm}^{-1}$ was observed, this peak was

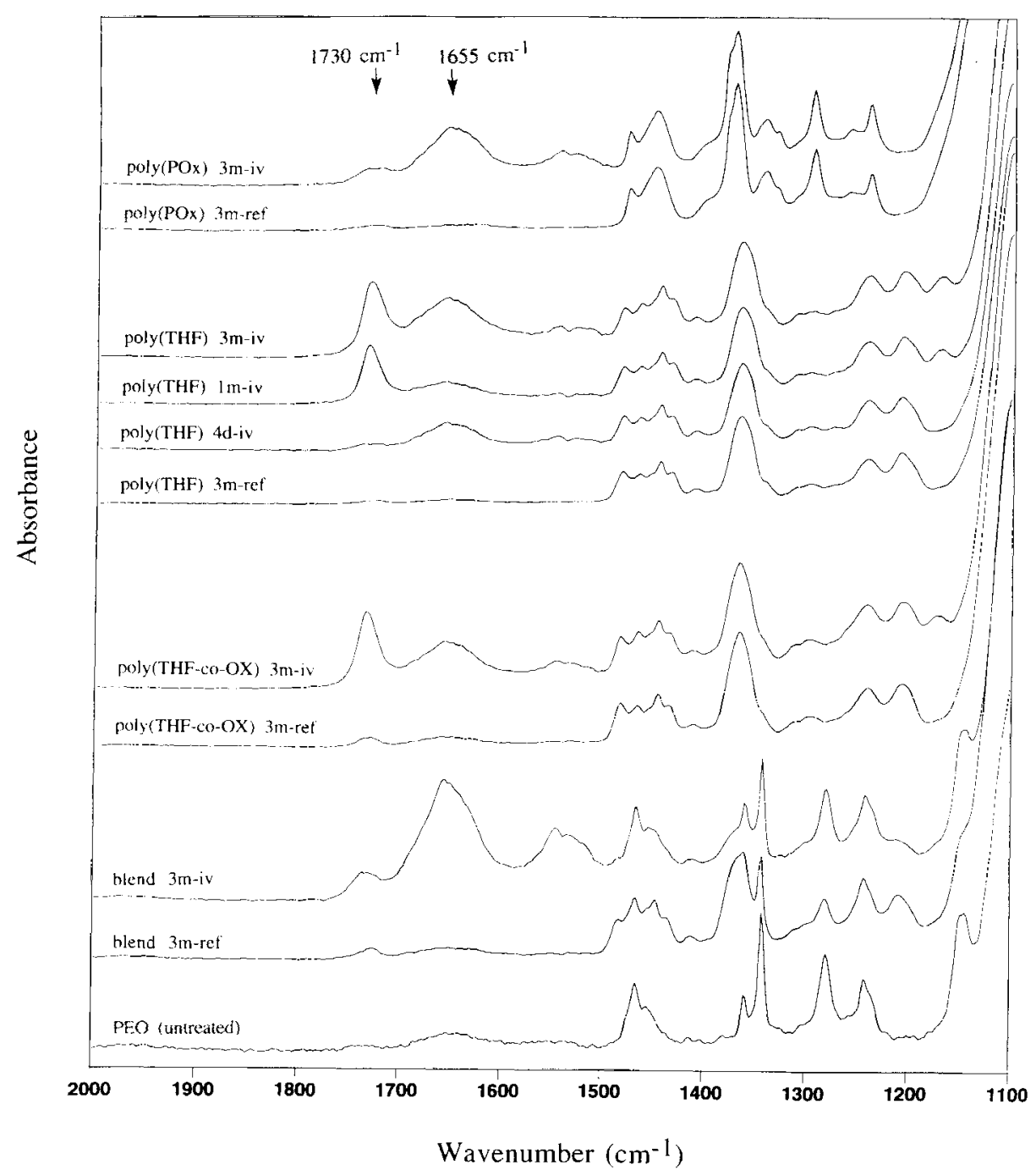

Figure 1. ATR-IR spectra of explanted and reference samples. ( $m$, month(s); d, days; iv, in vivo sample; ref, reference sample). 


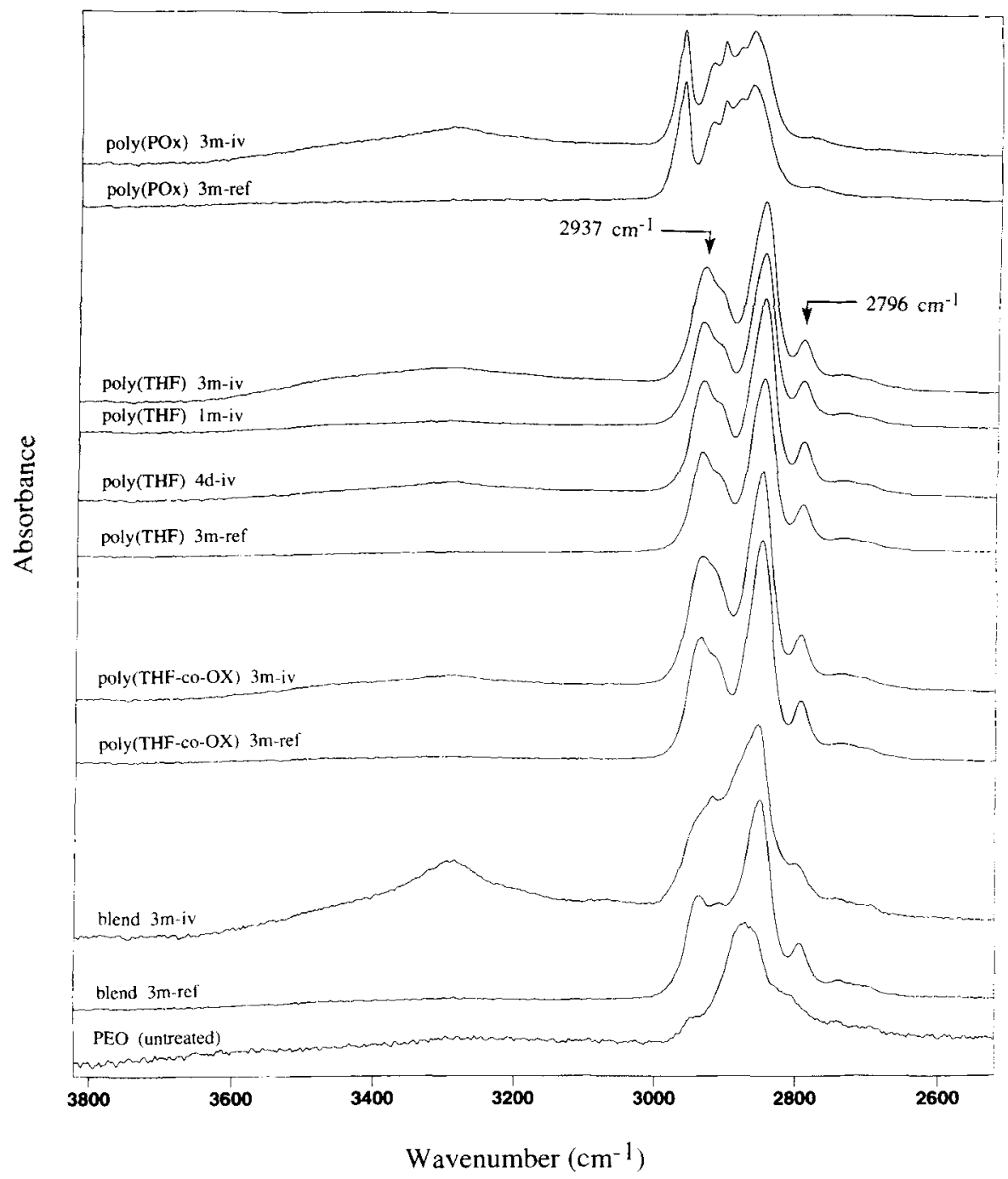

Figure 2. ATR-IR spectra of explanted and reference samples. (m, month(s); d, days; iv, in vivo sample; ref, reference sample).

much more pronounced for the 1- and 3-month samples. After 1 month of implantation a peak at $1170 \mathrm{~cm}^{-1}$ appeared, which seems to be related to the one at $1730 \mathrm{~cm}^{-1}$. A peak at $1655 \mathrm{~cm}^{-1}$ already was clearly present after 4 days of implantation. Another change in the spectra, as a function of the implantation time, was the relative decrease of the intensity of the peaks at $2796 \mathrm{~cm}^{-1}$ and $1482 \mathrm{~cm}^{-1}\left(\alpha-\mathrm{CH}_{2}\right)$ compared to the peaks at $2937 \mathrm{~cm}^{-1}$ and $1446 \mathrm{~cm}^{-1}\left(\beta-\mathrm{CH}_{2}\right)$ (Fig. 2).

Similar to the observations for poly(THF), a small peak was found at $1730 \mathrm{~cm}^{-1}$ after 4-days implantation of poly(THF-Co-OX), and this peak was more pronounced after 1 and 3 months. A small band at $1655 \mathrm{~cm}^{-1}$ was visible after 4 days of implantation and this band also increased with implantation time. The reference samples after 1 and 3 months showed weak absorptions at 1730 and $1655 \mathrm{~cm}^{-1}$ and $1545 \mathrm{~cm}^{-1}$, with intensities comparable to those of the in vivo sample of 4-day implantation. Also for poly(THF-co-OX) a relative decrease of the intensities of the peaks at 2796 and $1482 \mathrm{~cm}^{-1}$ was found.
Hydrophilic materials

After 4-days implantation of the poly(THF)/PEO blend, a band at $1655 \mathrm{~cm}^{-1}$ was visible together with a small absorption at $1730 \mathrm{~cm}^{-1}$. The band at $1730 \mathrm{~cm}^{-1}$ increased only slightly with implantation time, but the $1655 \mathrm{~cm}^{-1}$ absorption increased more strongly (Fig. 1). After 3-months implantation a peak at $1545 \mathrm{~cm}^{-1}$ also was clearly present. A noticeable decrease in intensity was observed for the bands at 1482, 1446, 1433, 1366, and $1208 \mathrm{~cm}^{-1}$, all characteristic of poly(THF), and an increase of the intensity of the bands at 1466, 1345, 1282 , and $1148 \mathrm{~cm}^{-1}$, which is characteristic of PEO. For comparison the spectrum of untreated $\mathrm{PEO}$ also is given in Figures 1 and 2 .

\section{DISCUSSION}

The changes in the degree of swelling and in the sol fraction of the explants, as well as of the reference 
samples (Table II), are probably due not only to degradation of the surface, but also to the bulk of the samples, as observed by Meijs et al. in the in vitro degradation of poly(ether urethane)s in a hydrogen peroxide solution. ${ }^{6}$ The results obtained for the weight loss, the swelling, and the sol fraction of the hydrophobic polyethers confirm our conclusion from Part I that poly $(\mathrm{POx})$ possesses the lowest resistance to degradation. In vivo more than $40 \%$ of the initial weight was lost after 3-months implantation, and this can be explained by the pronounced phagocytic activity of giant cells as observed with $\mathrm{LM}{ }^{15}{ }^{15}$ Similar high degradation rates for poly $(\mathrm{POx})$ in vivo in rats were reported by Bakker et al., who found a decrease of more than $50 \%$ of the cross-sectional area of implanted poly(POx) samples 13 weeks postimplantation and a high extent of phagocytosis. ${ }^{19,20}$ Next to the presence of tertiary hydrogen atoms, catalyst residues may be a possible cause for the poor stability of poly(POx). ${ }^{21}$

Although less pronounced than with poly(POx), the results for poly(THF) and poly(THF-co-OX) indicate that with these (co)polyethers also (bio)degradation had taken place. The higher stability of poly(THF) and poly(THF-co-OX) compared to poly(POx) might be due to a higher reactivity to tertiary than to secondary (or primary) carbon atoms. ${ }^{22,23}$ The loss of transparency for the explanted samples of poly(THF) and poly(THFco-OX) might be considered signs of biodegradation, as has been reported by Wu et al. for the in vivo degradation of poly(ether urethane)s. ${ }^{2}$ Although phagocytosis was not observed for poly(THF) even 3 months postimplantation, a weight loss of the explanted samples was found, possibly indicating that low-molecular-weight degradation products were removed by the collagenase-washing procedure of the explanted samples.

The weight loss, swelling, and sol fraction of the in vivo samples of $\mathrm{PEO}$ are difficult to interpret because of the presence of cellular material. Incomplete removal of the cellular material probably was a consequence of ingrowth of cellular material into the hydrophilic, and therefore highly swollen, PEO network, which made the cellular material difficult to remove afterwards. Compared to the reference samples of poly (THF) and of poly(THF-co-OX), the reference samples of PEO showed a high swelling in aqueous media. Therefore the crosslinked polymeric chains are constantly under tension, which leads to a higher energetic level of the chains and makes the network more vulnerable to degradation reactions. For comparison, Ellis et al. reported about an increasing swelling with duration of immersion for crosslinked natural rubber in benzene. The increment after diffusion equilibrium generally was believed to be due to oxidative degradation of the network in the swollen state. ${ }^{24}$

Furthermore the high swelling results in an increased accessibility of the polymeric chains to oxida- tive attack. Not only is the ease of invasion of cellular material enhanced, as was reported earlier for PEO only 4 days postimplantation, ${ }^{15}$ but also the permeability of the network for oxidizing agents is much higher. Tyler et al. ${ }^{25}$ reported that permeability plays an important role in the degradation of poly(ether urethane)s by hydrogen peroxide. Swelling of the poly(ether urethane)s in hydrogen peroxide was proposed to be due to the formation of hydrophilic groups in reaction to hydrogen peroxide and was assumed to accelerate the rate of degradation by enhancing the transport of water and hydrogen peroxide into the bulk of the polymer. In addition to these phenomena arising from the hydrophilicity of the PEO network, structural aspects also may play an important role in (bio)degradation. The polymeric backbone of PEO consists exclusively of $\alpha$-methylene groups, which are reported to be sensitive to oxidative attack. ${ }^{6,7}$ The susceptibility of PEO to degradation also was reported by Santacesaria et al. for the autoxidation of PEO at room temperature..$^{26}$ In addition, other reports from the literature indicate that even traces of oxygen can initiate PEO degradation at moderate temperatures. ${ }^{27,28}$ Bortel et al. observed that degradation of high-molecular-weight PEO can take place even at room temperature in the absence of oxygen. ${ }^{27}$ Furthermore, in our study, a certain amount of tertiary carbon atoms was introduced into the network as a result of the UV-induced crosslinking of the PEO with $6 \mathrm{phr}$ DCP, and degradation reactions possibly were initiated at these sites. Kohjiya et al. studied linear polyetherurethaneureas containing linear low molecular weight PEO-poly(THF)-PEO triblock copolyethers as soft segments. ${ }^{29}$ In contrast to the significant increases in the swelling of the PEOcontaining reference samples that we found as a function of time, they did not observe any significant increases in swelling even after 6 months of soaking in saline solution at $37^{\circ} \mathrm{C}$. This might indicate that the tertiary hydrogen atoms introduced by chemical crosslinking may plan an important role in the degradation of our crosslinked PEO-containing samples. Additionally, the tension of the network due to the swelling concentrates on these crosslinking sites.

Due to the high swelling in water of the PEO samples, it is difficult to evaluate a possible effect of the chemical structure of PEO on the degradation in comparison with that of the hydrophobic polyethers. In order to gain more insight with respect to the different behaviors of the polyethers, we also tested them in the dry state by thermogravimetric analysis (TGA) and differential scanning calorimetry (DSC). The stability in an oxygen-rich environment (air) was tested with heat as well as by isothermal ageing experiments, and the heat evolution and the weight loss were recorded simultaneously. The results from the isothermal ageing experiments are represented in Figure 3, indicating the following increasing order of stability: poly $(\mathrm{POx}) \leq$ 

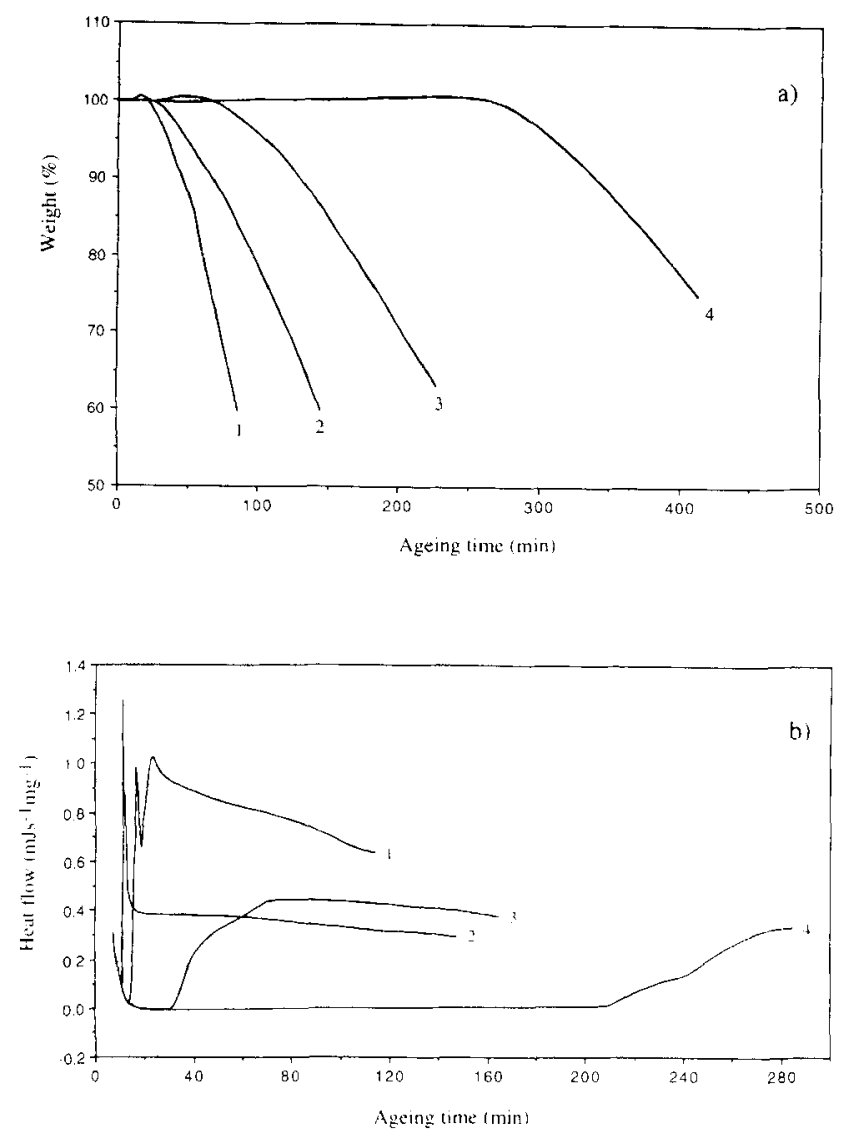

Figure 3. Isothermal ageing of crosslinked polyethers at $120^{\circ} \mathrm{C}$ in air: (a) weight loss, and (b) heat flow as a function of ageing time; (1) poly(POx); (2) PEO; (3) poly(THF-co-OX); (4) poly(THF).

PEO $<$ poly $($ THF-co-OX $)<$ poly $($ THF $) .{ }^{30}$ The fact that poly(POx) showed the lowest stability is in agreement with the proposed negative effect of tertiary hydrogen atoms on the oxidative stability. The sequence PEO $<$ poly (THF-co-OX) $<$ poly (THF) indicates that a lower amount from $\alpha$-methylene groups leads to more stable materials, as will be discussed below.

Large weight increases, such as observed for the in vivo samples of $\mathrm{PEO}$, were not found for the poly(THF)/PEO blend, although some cellular material still might have been present. This might be caused by the much lower swelling in water of the blend compared to PEO, which decreases the ease of the invasion of cells. Noteworthy is the gradual increase with implantation time of the PEO content on the surface of the blend, as shown by IR analysis. This seems to be in contrast with the findings for the reference samples, which demonstrated that PEO degraded faster than poly(THF). It is conceivable, however, that during implantation, the PEO domains in the blend are preferentially attacked and penetrated by small pseudopods of macrophages. In Part I of this study, it was shown that for the poly(THF)/PEO blend a frayed morphology had developed, which became more pronounced with increasing implantation time..$^{15} \mathrm{~A}$ frayed morphology will result in an increase in the total surface area, which will consist of a relatively higher amount of PEO due to preferential attack of the PEO domains.

The considerable weight loss and/or sol fraction observed for the reference samples of poly(POx) and PEO after only 4 days also might indicate that the ethylene oxide sterilization procedure contributed to degradation. However, compared to poly(POx), the other hydrophobic polyethers, poly(THF) and poly(THF-coOX), did not show such high values for the weight loss and sol fraction. Unlike these polyethers, poly(POx) contains tertiary hydrogen atoms that might be the cause of the faster degradation of poly(POx).

\section{Degradation mechanism}

After implantation of a foreign body, such as a polymer sample, macrophages adhere quickly to the surface, become activated, and can form foreign-body giant cells. These phagocytic cells release superoxide anions, hydrogen peroxide, hypochlorite, and (hydrolytic) enzymes, and local concentrations of these products can become high., ${ }^{2,6-8,31-33}$ Furthermore the interfacial environment changes into the acidic range. Adsorption of $\alpha_{2}$-macroglobulin also has been reported to play an important role in biodegradation. ${ }^{14}$ Based on the results mentioned in the preceding paragraphs, a possible mechanism now will be discussed for the observed degradation. The appearance of new bands in the IR spectra of the explanted hydrophobic polyether samples might be explained by assuming a mechanism similar to that proposed by $\mathrm{Wu}$ et al. ${ }^{7}$ for the in vivo degradation of poly(ether urethane)s with poly(THF) as the soft segment (Fig. 4, path (1)) and/or by assuming a mechanism for the autoxidation of polyethers (path (2) in Fig. 4). ${ }^{22,26,27,32}$ Figure 4 shows the proposed degradation mechanism with poly(THF) as an example.

$\mathrm{Wu}$ et al. reported that superoxide anion radicals combine rapidly with protons to form hydroperoxide radicals $\mathrm{HOO}^{\circ}$, which attack the polymer backbone leading to the hydroperoxide groups $\mathrm{POOH}$ (Fig. 4). ${ }^{7}$ According to $\mathrm{Wu}$ et al., the hydroperoxide subsequently will dehydrate to form an ester, which then will hydrolyze due to esterases, leading to chain scission and resulting in the formation of carboxylic acid and alcohol groups. ${ }^{7}$ Schubert et al. suggest that the radicals $\mathrm{P}^{\bullet}$ might be formed by hydrogen abstraction from the polyether soft segment by thiyl radicals that formed after reaction of hydroxy radicals with free thiol groups of (adsorbed) $\alpha_{2}$-macroglobulin (not shown in Fig. 4). ${ }^{14}$

Another form of degradation (autoxidation) can take place by way of a variety of reaction paths, all involving radical mechanisms. In short the propagation reactions 


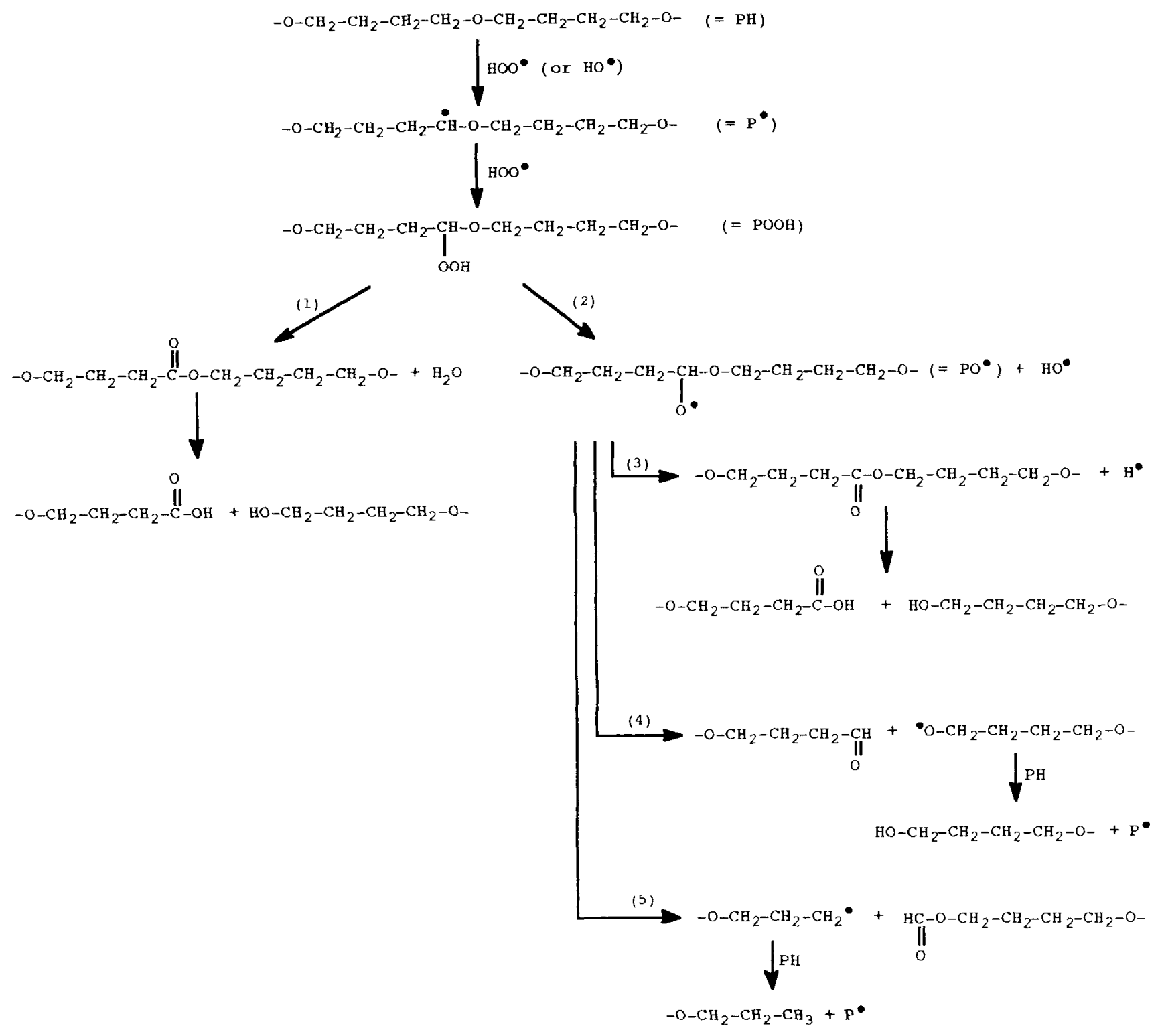

Figure 4. Proposed mechanism for the in vivo degradation of poly(THF).

of this autoxidation consist of the formation and decomposition of hydroperoxide groups on the polymer backbone (POOH in Fig. 4). Homolysis of the hydroperoxide leads to hydroxyl and alcoxy radicals ( $\left.\mathrm{PO}^{*}\right)$. The latter can form an ester by hydrogen fragmentation [(3) in Fig. 4] or can lead to chain scission, resulting in the formation of aldehyde and ester groups [(4) and (5) in Fig. 4]. These reactions occur without the loss of radical activity, and the remaining radicals can continue the degradation. Hydrolysis of the ester bonds will lead to the formation of alcohol and acid groups.

The most prominent new absorptions in the IR spectra were the bands at 3600-3100, 1730, 1655, and $1170 \mathrm{~cm}^{-1}$, most of them originating from oxygencontaining groups (Table III). The broad band at $3600-3100 \mathrm{~cm}^{-1}$ is characteristic for the presence of $\mathrm{O}-\mathrm{H}$ containing groups such as carboxylic acids and alcohols. This band also might indicate the presence of hydroperoxides because they have been reported to be relatively stable at moderate temperatures. ${ }^{6,22}$ The carbonyl band at $\pm 1730 \mathrm{~cm}^{-1}$ could be the result of carboxylic ester or aldehydes. The peak at $\pm 1170 \mathrm{~cm}^{-1}$ can be attributed to the presence of carboxylic ester groups, although Thoma et al. suggested that the IR peak at $1174 \mathrm{~cm}^{-1}$ might be the result of coordination of the ether oxygen with a metal ion. ${ }^{34}$ Since no metals are used in our study, the attribution to ether oxygen/ metal ion coordination is not very likely. In biodegradation studies of poly(ether urethane)s, $\mathrm{Wu}$ et al. ${ }^{7} \mathrm{ob}-$ served a new absorption peak at $1174 \mathrm{~cm}^{-1}$ and assigned this to carboxylic ester or acid. However, Schubert et al. noted that this absorbance also might be an indication of "branched ether," formed due to crosslinking of the polyether soft segment. ${ }^{14}$ For perox- 
ide-crosslinked polyethers, which were not treated in vivo or under the reference conditions, we did not find such an absorption. Thus, Schubert's assignment does not seem to be valid for our systems, and we attributed the absorption to the presence of carboxylic ester groups. Since the intensities of the absorptions at $1730 \mathrm{~cm}^{-1}$ and $1170 \mathrm{~cm}^{-1}$ seem to be coupled, we ascribed the $1730 \mathrm{~cm}^{-1}$ absorption to carboxylic ester groups, although the presence of aldehyde groups cannot be excluded beforehand. That the presence of aldehyde groups could not unequivocally be confirmed spectrally for any of the tested materials might indicate that their formation is less likely or that they are relatively unstable and are oxidized to acid rapidly after their formation. ${ }^{1}$ The band at $\pm 1655 \mathrm{~cm}^{-1}$ was ascribed to the presence of carboxylic acid groups (or alkene) and is in agreement with the assignments made by Zhao et al. ${ }^{1}$ and Wu et al. ${ }^{7}$ for their in vivo degradation studies of poly(ether urethane)s.

The small carbonyl band at $\pm 1730 \mathrm{~cm}^{-1}$ in the spectra of the in vivo samples of poly(POx) might indicate the presence of ester groups. The high intensity of the band at $1655 \mathrm{~cm}^{-1}$ (acid) suggests a rapid hydrolysis of formed ester bonds. For poly(POx) the formation of ester according to route (1) would involve the production of toxic methanol instead of water although no toxic effects were found during our in vivo study. In addition to methanol, toxic aldehydes, such as acetaldehyde, are reported to be degradation products of poly(POx). ${ }^{22}$ In an in vivo study of poly(POx) with rats, Bakker et al. ${ }^{19}$ reported on toxic effects leading to the untimely death of rats and probably caused by aldehydes released during the breakdown of poly(POx). Considering our proposed mechanism, the production of methanol also might have contributed to such deaths. Noteworthy is the almost complete absence of the carbonyl bands for the reference samples of poly(POx) even though severe degradation had occurred, as was shown by the weight loss after treatment and the swelling behavior.

For poly(THF) and poly(THF-co-OX) the absorptions at $1655 \mathrm{~cm}^{-1}$ (acid) initially (after 4 days in vivo) were more pronounced than the band at $\pm 1730 \mathrm{~cm}^{-1}$ (ester). After 3 months of implantation, both absorptions were clearly present. A possible explanation for the increase of the ester absorption from 4 days to 1 month is that ester groups formed in the earlier stage of implantation at the near surface of the polyethers were more quickly hydrolyzed as compared to ester groups formed in the bulk after longer implantation times. Because only a small absorption for poly(POx) was found at $1730 \mathrm{~cm}^{-1}$, hydrolysis of ester bonds possibly occurred more rapidly for poly(POx) than for poly(THF) and poly(THF-co-OX).

Pinchuk proposed that because of the low $\mathrm{pH}$ in the vicinity of macrophages and giant cells, chain cleavage by acid hydrolysis also might be responsible for the degradation of poly(ether urethane)s. ${ }^{13}$ According to that mechanism no carboxylic ester and/or acid groups would be formed, which means that our results do not support their mechanism.

The peak at $\pm 1540 \mathrm{~cm}^{-1}$, observed not only for poly(THF) and poly(THF-co-OX) but also for poly (POx), PEO, and the blend, might be ascribed to irreversible adsorption of collagenase during the work-up procedure and may reflect the amide II peak. Adsorption of proteins on solid surfaces is well known; e.g., Phua et al. ${ }^{12}$ found IR peaks at $1653 \mathrm{~cm}^{-1}$ (amide I) and $1550 \mathrm{~cm}^{-1}$ (amide II) on the surface of Biomer due to irreversible protein adsorption. In a degradation study of poly(ether urethane)s in a protein solution, Takahara et $\mathrm{al}^{3}{ }^{3}$ also observed amide I and amide II absorptions in ATR-IR spectra of a poly(ether urethane) with PEO as the soft segment, which was ascribed to either absorption or adsorption of proteins. For the in vivo samples in our study it also is possible that the peaks at $\pm 1540 \mathrm{~cm}^{-1}$ are due to (extracellular matrix) protein deposition on the material, as observed by light microscopic evaluation for the 1-month blend..$^{15}$ If this band resulted from adsorbed proteins, then the absorption at $1680-1620 \mathrm{~cm}^{-1}$ may not be ascribed exclusively to carboxylic acid groups, but also partly to the amide I band of proteins.

To investigate the site at which oxidative attack of poly(THF) and poly(THF-co-OX) occurs, a distinction has to be made between $\alpha$-methylene and $\beta$-methylene groups. Preferential oxidation of one of the types will lead to a change in the ratio of their amounts present in the degraded samples. The ratio of the intensity of the IR absorptions characteristic for the $\beta$-methylene group $\left(\nu_{a}\left(\mathrm{CH}_{2}\right)_{\beta}\right.$ (asymmetric stretching) at $\left.2937 \mathrm{~cm}^{-1}\right)$ and that for the $\alpha$-methylene group $\left(\nu_{\mathrm{s}}\left(\mathrm{CH}_{2}\right)_{\alpha}\right.$ (symmetric stretching) at $\left.2796 \mathrm{~cm}^{-1}\right)^{35}$ was calculated by dividing the corresponding values of the absorbances $A_{\beta}$ and $\mathrm{A}_{\alpha}$ (Table IV): $\mathrm{R}_{1}-\mathrm{CH}_{2}^{\beta}-\mathrm{CH}_{2}^{\alpha}-\mathrm{CH}_{2}-\mathrm{O}-\mathrm{R}_{2}$.

From Table IV it is clear that the $\alpha$-methylene groups are more sensitive to oxidation than are the $\beta$ -

TABLE IV

Ratios of IR Absorbances of $\beta-\mathrm{CH}_{2}$ Groups $\left(A_{\beta}\right.$, at $\left.2937 \mathrm{~cm}^{-1}\right)$ and $\alpha-\mathrm{CH}_{2}$ Groups $\left(\mathrm{A}_{\alpha}\right.$ at $\left.2796 \mathrm{~cm}^{-1}\right)$

\begin{tabular}{lll}
\hline & \multicolumn{2}{c}{$\mathrm{A}_{\beta} / \mathrm{A}_{\alpha}$} \\
\cline { 3 - 3 } & in vivo & Ref. \\
\hline Poly(THF): & 2.20 & $2.15^{\mathrm{a}}$ \\
4 days: & 2.33 & $2.16^{\mathrm{a}}$ \\
1 month: & 2.44 & 2.16 \\
3 months: & & \\
Poly(THF-co-OX) b $^{\mathrm{b}}$ & $2.11^{\mathrm{a}}$ & $2.07^{\mathrm{a}}$ \\
4 days: & $2.38^{\mathrm{a}}$ & $2.08^{\mathrm{a}}$ \\
1 month: & 2.41 & 2.10 \\
\hline 3 months: & &
\end{tabular}

aSpectra not shown.

${ }^{b}$ Consisting of 83 mole $\%$ tetrahydrofuran (THF) units and 17 mole\% oxetane (OX) units. 
methylene groups. These results are in agreement with those from studies on the degradation of poly(ether urethane)s with poly(THF) as the soft segment $t^{6,7}$ and can be explained as suggested by Grassie et al. that oxygen attached to carbon activates the $\alpha$-carbon atom to peroxidation reactions. ${ }^{23}$ Next to attack on the $\alpha$ methylene groups, a less probable degradation by hydrogen abstraction from $\beta$-methylene groups, leading to formation of alkene bonds, was suggested by Zhao et al. ${ }^{1}$ However, the observed increase in the absorptions at $1655 \mathrm{~cm}^{-1}$ and at $3600-3100 \mathrm{~cm}^{-1}$ and the increase of the ratio $\mathrm{A}_{\beta} / \mathrm{A}_{\alpha}$, support the assignment of these bands to acid instead of to alkene groups, which means that there are no indications of the occurrence of $\beta$ attack, although it cannot be excluded.

Considering the higher sensitivity to oxidation of the $\alpha$-methylene groups, the somewhat higher stability of poly(THF) over poly(THF-co-OX) might be a result of the lower number of $\alpha$-methylene groups in the former. This is in agreement with the hypothesis of Gunatillake et al., that the resistance to oxidation of poly(ether urethane)s will increase with increasing $\mathrm{C} / \mathrm{O}$ ratio of the polyether soft segment.

\section{CONCLUSIONS}

Using subcutaneous implantation in rats, the effect of implantation on the surface and bulk properties of several crosslinked polyethers was studied as a function of the implantation time. For the relatively hydrophobic polyethers studied, the biostability, in terms of weight loss, increase in swelling, and in sol fraction, increased in the order poly(POx) $<$ poly (THF-co-OX) $<$ poly(THF). This is in agreement with the results from our microscopical evaluation reported in Part I and confirms our hypothesis that the absence of tertiary hydrogen atoms would improve the biostability. ${ }^{15}$ Biodegradation consisted of oxidative attack on the polymeric chain, leading to the formation of carboxylic ester and acid groups. It also was observed that among the THF-based (co)polyethers, $\alpha$-methylene groups were more sensitive than $\beta$-methylene groups. For the poly(THF)/PEO blend an increase in surface PEO content was found, which might be due to preferential degradation of the PEO domains resulting in the frayed morphology observed after implantation.

In conclusion, a significant improvement with respect to the biostability of poly(POx) was obtained by applying polyethers without tertiary hydrogen atoms. However, signs of biodegradation still were observed, and that degradation probably was due to the presence of $\alpha$-methylene groups in the polyethers. Therefore a further improvement of the biostability might be achieved by diminishing the number of these susceptible groups.

\section{References}

1. Q. H. Zhao, A. K. McNally, K. R. Rubin, M. Reinier, Y. Wu, V. Rose-Caprara, J. M. Anderson, A. Hiltner, P. Urbansky, and K. Stokes, "Human plasma $\alpha_{2}-$ macroglobulin promotes in vitro oxidative stress cracking of Pellethane 2363-80A: In vivo and in vitro correlations," J. Biomed. Mater. Res., 27, 379-389 (1993).

2. Y. Wu, Q. Zhao, J. M. Anderson, A. Hiltner, G. A. Lodoen, and C. R. Payet, "Effect of some additives on the biostability of a poly(etherurethane) elastomer," J. Biomed. Mater, Res., 25, 725-739 (1991).

3. A. Takahara, R. W. Hergenrother, A. J. Coury, and S. L. Cooper, "Effect of soft segment chemistry on the biostability of segmented polyurethanes. II. In vitro hydrolytic degradation and lipid sorption," J. Biomed. Mater. Res., 26, 801-818 (1992).

4. P. A. Gunatillake, G. F. Meijs, E. Rizzardo, R. C. Chatelier, S. J. McCarthy, A. Brandwood, and K. Schildhelm, "Polyurethane elastomers based on novel polyether macrodiols and MDI: Synthesis, mechanical properties, and resistance to hydrolysis and oxidation," J. Appl. Polym. Sci., 46, 319-328 (1992).

5. B. D. Ratner, K. W. Gladhill, and T. A. Horbett, "Analysis of in vitro enzymatic and oxidative degradation of polyurethanes," J. Biomed. Mater. Res., 22, 509-527 (1988).

6. G. F. Meijs, S. J. McCarthy, E. Rizzardo, Y. Chen, R. C. Chatelier, A. Brandwood, and K. Schindhelm, "Degradation of medical-grade polyurethane elastomers: The effect of hydrogen peroxide in vitro," J. Biomed. Mater. Res., 27, 345-356 (1993).

7. Y. Wu, C. Sellitti, J. M. Anderson, A. Hiltner, G. A. Lodoen, and C. R. Payet, "An FTIR-ATR investigation of in vivo poly(ether urethane) degradation," J. Appl. Polym. Sci., 46, 201-211 (1992).

8. A. Takahara, A. J. Coury, R. W. Hergenrother, and S. L. Cooper, "Effect of soft segment chemistry on the biostability of segmented polyurethanes. I. In vitro oxidation," J. Biomed. Mater. Res., 25, 341-356 (1991).

9. A. Brandwood, G. M. Meijs, P. A. Gunatillake, K. R. Noble, K. Schindhelm, and E. Rizardo, "In vivo evaluation of polyurethanes based on novel macrodiols and MDI," J. Biomater. Sci. Polym. Edn., 6, 41-54 (1994).

10. J. G. Dillon, and M. K. Hughes, "Degradation of five polyurethane gastric bubbles following in vivo use: SEC, ATR-IR, and DSC studies," Biomaterials, 13, 240-248 (1992).

11. J. P. Santerre, R. S. Labow, and G. A. Adams, "Enzymebiomaterial interactions: Effect of biosystems on degradation of polyurethanes," I. Biomed. Mater. Res., 27, 97109 (1993).

12. S. K. Phua, E. Castillo, J. M. Anderson, and A. Hiltner, "Biodegradation of a polyurethane in vitro," J. Biomed. Mater. Res., 21, 231-246 (1987).

13. L. Pinchuk, "Review. A Review of the biostability and carcinogenicity of polyurethanes in medicine and the new generation of 'biostable' polyurethanes," J. Biomater. Sci. Polym. Edn., 6, 225-267 (1994).

14. M. A. Schubert, M. J. Wiggins, M. P. Schaefer, A. Hiltner, and J. M. Anderson, "Oxidative biodegradation mechanisms of biaxially strained poly(etherurethane urea) elastomers," J. Biomed. Mater. Res., 29, 337-347 (1995).

15. B. J. M. Pol, P. B. van Wachem, M. J. A. van Luyn, L. van der Does, and A. Bantjes, "In vivo testing of crosslinked polyethers. I. Tissue reactions and interactions," J. Biomed. Mater. Res.," 32, 307-320 (1996). 
16. D. Lin-Vein, N. B. Colthup, W. G. Fateley, and J. G. Graselli, The Handbook of IR and Raman Characteristic Frequencies of Organic Molecules, Academic Press, Inc., Boston, 1991.

17. H. Volkman, Handbuch der Infrarot-Spektroskopie, Verlag Chemie GmbH, Germany, 1972.

18. L. J. Bellamy, The Infrared Spectra of Complex Molecules, Methuen and Co. Ltd., London, 1964.

19. D. Bakker, C. A. van Blitterswijk, S. C. Hesseling, J. J. Grote, and W. T. Daems, "Effect of implantation site on phagocyte/polymer interaction and fibrous capsule formation," Biomaterials, 9, 14-23 (1988).

20. D. Bakker, C. A. van Blitterswijk, S. C. Hesseling, W. T. Daems, W. Kuijpers, and J. J. Grote, "The behavior of alloplastic tympanic membranes in Staphylococcus aureus-induced middle ear infection. I. Quantitative biocompatibility evaluation," J. Biomed. Mater. Res., 24, 669-688 (1990).

21. J. G. F. Bots, "Polyethers as biomaterials," Ph.D. Thesis, University of Twente, Enschede, The Netherlands, 1988.

22. P. J. F. Griffiths, J. G. Hughes, and G. S. Park, "The autoxidation of poly(propylene oxide)s," Eur. Polym. J., 29, 437-442 (1993).

23. N. Grassie, The Chemistry of High Polymer Degradation Processes, Buttersworths, London, 1956.

24. B. Ellis and G. N. Welding, "Estimation, from swelling, of the structural contribution of chemical reactions to the vulcanization of natural rubber. Part II. Estimation of equilibrium degree of swelling," Rubber Chem. $\mathcal{E}$ Tech., 37, 571-575 (1964).

25. B. J. Tyler and B. D. Ratner, "Variation between Biomer lots. II. The effect of differences between lots on in vitro enzymatic and oxidative degradation of a commercial polyurethane," I. Biomed. Mater. Res., 27, 327-334 (1993).

26. E. Santacesaria, D. Gelosa, M. di Serio, and R. Tesser "Thermal stability of nonionic polyoxyalkylene surfactants," I. Appl. Polym. Sci., 42, 2053-2061 (1991).

27. E. Bortel and R. L. Lamot, "Untersuchung des Abbaus hochmolekularer Polyäthylenoxide im Festzustand," Makromol. Chem., 178, 2617-2628 (1977).
28. G. K. Jones, A. R. McGhie, and G. C. Farrington, "Studies of the stability of poly(ethylene oxide) and PEObased solid electrolytes using thermogravimetry-mass spectrometry," Macromolecules, 214, 3285-3290 (1991).

29. S. Kohjiya, Y. Ikeda, and S. Yamashita, "Properties of segmented polyurethaneurea based on PEO-PTHFPEO triblock copolymer for biomedical uses," in Polyurethanes in Biomedical Engineering II, H. Planck, I. Syré, M. Dauner, and G. Egbers (eds.), Elseviers Science Publishers BV, Amsterdam, 1987, pp. 183-195.

30. B. J. M. Pol, "Elastomeric crosslinked polyethers for biomedical applications," Ph.D. Thesis, Enschede, The Netherlands, 1995, pp. 135-140.

31. Q. Zhao, N. Topham, J. M. Anderson, A. Hiltner, G. Lodoen, and C. R. Payet, "Foreign-body giant cells and polyurethane biostability: In vivo correlation of cell adhesion and surface cracking," J. Biomed. Mater. Res., 25, 177-183 (1991).

32. K. Stokes, P. Urbansky, and J. Upton, "The in vivo autooxidation of polyether polyurethane by metal ions," J. Biomater. Sci. Polym. Edn., 1, 207-230 (1990).

33. W. J. Kao, Q. H. Zhao, A. Hiltner, and J. M. Anderson, "Theoretical analysis of in vivo macrophage adhesion and foreign body giant cell formation on polydimethylsiloxane, low density polyethylene, and polyetherurethanes," J. Biomed. Mater. Res., 28, 73-79 (1994).

34. R.J. Thoma, "Poly(ether) urethane reactivity with metal-ion in calcification and environmental stress cracking," J. Biomater. Appl., 1, 449-486 (1986).

35. K. Ymada, H. Tadokoro, A. Umehara, and S. Murahashi, "Normal vibrations of the polymer molecules of helical conformation. VI. Polytetrahydrofuran and deuterated polytetrahydrofurans," J. Chem. Phys., 42, 2807-2816 (1965).

Received July 5, 1995

Accepted December 14, 1995 